\title{
Patient Tracking System
}

National Cancer Institute

\section{Source}

National Cancer Institute. Patient Tracking System. NCI Thesaurus. Code C74928.

A computerized system for tracking the status and location of a patient as they move through a medical facility. 